\title{
Beneficial Effects of Pomegranate Peel Extract and Probiotics on Pre-adipocyte Differentiation
}

\author{
Valeria Sorrenti ${ }^{*}$, Cinzia Lucia Randazzo², Cinzia Caggia², Gabriele Ballistreri, \\ Flora Valeria Romeo ${ }^{3}$, Simona Fabroni ${ }^{3}$, Nicolina Timpanaro ${ }^{3}$, Marco Raffaele ${ }^{1}$ and \\ Luca Vanella ${ }^{1}$ \\ ${ }^{1}$ Dipartimento di Scienze del Farmaco, Sezione di Biochimica, Università di Catania, Catania, Italy, ${ }^{2}$ Dipartimento di \\ Agricoltura, Alimentazione e Ambiente - Di3A, Università di Catania, Catania, Italy, ${ }^{3}$ Council for Agricultural Research \\ and Economics (CREA) - Research Centre for Olive, Citrus and Tree Fruit, Acireale, Italy
}

\section{OPEN ACCESS}

Edited by:

Rosalba Lanciotti,

University of Bologna, Italy

Reviewed by:

Anna Reale,

Istituto di Scienza dell'Alimentazione

(ISA), Italy

Koshy Philip,

University of Malaya, Malaysia

${ }^{*}$ Correspondence: Valeria Sorrent

sorrenti@unict.it

Specialty section:

This article was submitted to

Food Microbiology,

a section of the journal

Frontiers in Microbiology

Received: 22 October 2018

Accepted: 15 March 2019

Published: 03 April 2019

Citation:

Sorrenti V, Randazzo CL,

Caggia C, Ballistreri G, Romeo FV,

Fabroni S, Timpanaro N, Raffaele $M$ and Vanella L (2019) Beneficial Effects

of Pomegranate Peel Extract and Probiotics on Pre-adipocyte

Differentiation.

Front. Microbiol. 10:660

doi: 10.3389/fmicb.2019.00660
The beneficial effects of pomegranate are due to the ellagitannins and anthocyanins content, which are protective toward a wide variety of diseases including inflammatory diseases. Many investigators have reported that pomegranate waste (peel and seeds) extracts, made from waste product of industrial processing, show free radical scavenger and a potent antioxidant capacity. Pomegranate extracts (PEs) were also reported to possess noteworty antibacterial, antiviral, hypolipidemic, and antiinflammatory bioactivities thanks to the polyphenolic compounds content, which includes punicalagins, gallic acid, and ellagic acid derivatives. The focus of the present manuscript was to study the prebiotic potentiality of a PE, soluble in water, and characterized through HPLC-PDA-ESI/MS ${ }^{n}$ for its phenolic content. Moreover, since it has been reported that pomegranate extracts decreased the level of lipids in the blood and that a number of probiotic strains have been shown to affect adipogenesis in cell culture, this study was also performed to test the in vitro effects of PE and probiotic L. rhamnosus GG ATCC 53103 strain (LGG) on 3T3-L1 cell line. PE and probiotics substantially reduced the triglyceride content and intracellular lipid increase, compared to the control group. However, the combination treatment of PE and LGG filtered spent broth (SB) was the most effective in reducing triglyceride content and intracellular lipid accumulation. The mRNA expression levels of the main transcriptional factors implicated in adipocyte differentiation were substantially lower in 3T3-L1 cells treated with PE and LGG filtered SB. These results evidenced that a synergistic effect of probiotics and polyphenols contained in PE may affect in vitro adipogenesis and may contribute in development of new nutraceutical/probiotic-based remedies to prevent and to treat obesity.

Keywords: lactobacilli, antimicrobial activity, pomegranate extract, adipocyte differentiation, combining foods

\section{INTRODUCTION}

Pomegranate is a fruit whose positive health effects have been extensively studied. This fruit is rich in bioactive compounds such as ellagitannins and anthocyanins content, which are protective toward degenerative diseases. Pomegranate fruit, because of its high nutritive value, health benefits, and antioxidant bioactive compounds, is considered as a food medicine. In fact, pomegranate has 
been considerably used in herbal medicine for several pathologies including flu and infections of the upper respiratory tract. All parts of the pomegranate fruit, i.e., peel and seeds, considered as waste products, can be processed for valueadded products having industrial, medicinal, and cosmetic value (Dhumal et al., 2014).

Pomegranate wastes are produced in all the phases of fruits life cycle, i.e., during agricultural production, industrial manufacturing, and processing. It is possible to take advantage of pomegranate by-products as they are a rich source of bioactive compounds such as flavonoids, phenolic acids, and tannins. Moreover, many researchers have described that pomegranate extracts, made from by-products of the processing factories, have an effective free radical scavenging activity and antioxidant capacity (Lee et al., 2010; Panichayupakaranant et al., 2010; Fischer et al., 2011).

Furthermore, the pomegranate extracts act as natural inhibitors of pathogens, bacteria, and fungi (Al-Zoreky, 2009; Tehranifar et al., 2011; Romeo et al., 2015).

Pomegranate ellagitannins are hydrolyzed by gut microbiota to smaller phenolics, such as ellagic acid. Ellagic acid is then absorbed into the blood circulation, while ellagitannins are not absorbed and are metabolized into urolithins.

It has been reported that pomegranate by-products and punicalagins significantly are able both to inhibit the growth of pathogenic Escherichia coli, Pseudomonas aeruginosa, Clostridia, and Staphylococcus aureus (Reddy et al., 2007; Bialonska et al., 2009) and to increase the growth on beneficial bacteria including Bifidobacterium spp. and Lactobacillus spp. (Reddy et al., 2007; Bialonska et al., 2010).

Pomegranate extracts were also reported to decrease the level of lipids in the blood and to have significant anticancer, antiviral, and anti-inflammatory activities (Li et al., 2006; Hossin, 2009; Lin et al., 2013; Bassiri-Jahromi, 2018).

These potential beneficial effects are attributed to the polyphenolic compounds that the pomegranate extracts contain including punicalagins, gallic acid, and ellagic acid derivatives (Vanella et al., 2013a,b,c; Romeo et al., 2015).

Because obesity is one of the main public health problems, new preventive strategies are necessary (Smith and Smith, 2016).

Adipocyte plays a major role in the begin or development of metabolic complications associated to obesity, such as metabolic syndrome and diabetic complications (Kim and Plutzky, 2016).

The interest of the researchers in the identification of natural products obtained from dietary plants that have anti-obesity activities has increased. It has been reported that the xanthigen and fucoxanthin, natural compounds of pomegranate seed oil, significantly suppressed adipocyte differentiation and lipid accumulation (Lai et al., 2012).

The focus of the present manuscript was firstly to study the antioxidant and antimicrobial activities, and the prebiotic potential of a $\mathrm{PE}$ rich in phenolic compounds. Moreover, the enriched standardized $\mathrm{PE}$, containing high percentages of pomegranate natural antioxidants, was chemically characterized through HPLC-PDA-ESI/MSn. Secondly, since pomegranate juice (Les et al., 2018) and different types of pomegranate extracts (PEs), including extract prepared from the whole fruit
(Li et al., 2015) and extract derived from pomegranate peel (Neyrinck et al., 2013), and a number of probiotic strains (Moon et al., 2012; Park et al., 2014) have been shown to affect adipogenesis, this study was carried out to test the in vitro effects of PE, probiotic L. rhamnosus GG ATCC 53103 (LGG) preincubated with $\mathrm{PE}$, alone or in combination, on 3T3-L1 cell differentiation.

\section{MATERIALS AND METHODS}

\section{Chemicals}

The powdered pomegranate extract (Dermogranate ${ }^{\circledR}$ ) employed in this study was provided by Medinutrex (Catania, Italy). Briefly, the extract was prepared from dried and grinded pomegranate fruits mixed with hydroalcoholic solutions (food grade) and then filtered. The filtrate was concentrated and then spray-dryed to obtain the standardized extract. The Dermogranate ${ }^{\circledR}$ extract had the following chemical composition: total polyphenols (16\%), punicalagins (8\%), ellagic acid, and derivatives (8\%).

Folin-Ciocalteu reagent (FCR), sodium carbonate $\left(\mathrm{Na}_{2} \mathrm{CO}_{3}\right)$, gallic acid, punicalin (mixture of anomers), punicalagin, and ellagic acid were purchased from Sigma-Aldrich (Milan, Italy). Granatin B was purchased from LGC Standards (London, United Kingdom). HPLC-MS grade solvents (Merck KgaA, Darmstadt,Germany) were used for chromatography and all other reagents were of analytical grade.

\section{Determination of Total Polyphenols Content}

The Folin-Ciocalteu assay (Singleton et al., 1999) was used for the determination of total polyphenols content with slight modifications. $0.1 \mathrm{mg} / \mathrm{ml}$ of extract was dissolved in distilled water. Then, $5 \mathrm{ml}$ of $10 \% \mathrm{FCR}$ and $4.5 \mathrm{ml}$ of $\mathrm{Na}_{2} \mathrm{CO}_{3}$ solution $(7.5 \% \mathrm{w} / \mathrm{v})$ were added to $500 \mu \mathrm{l}$ of sample. The final solution was agitated for $2 \mathrm{~h}$ in the dark and then the Abs at $\lambda=765 \mathrm{~nm}$ was measured. Analyses were carried out in triplicate and the concentration of total polyphenols was expressed as $\mathrm{g}$ of gallic acid equivalents (GAEs)/100 g of extract.

\section{HPLC-PDA-ESI/MS ${ }^{n}$ Analysis of Phenolic Compounds}

Separation and quantification of phenolic compounds were performed as previously described (Romeo et al., 2015). For the identification of phenolic compounds, the retention times (RTs), spectra, and MS data in negative ESI mode were compared to those of authentic standards. Quantification of each phenolic compound was performed using the corresponding standard as external standard. Quantification was carried out at $280 \mathrm{~nm}$ for gallic acid. Punicalins, granatin B, punicalagins, and ellagic acid were quantified at $378 \mathrm{~nm}$; the same wavelength was used for the quantification of ellagic acid derivatives using ellagic acid as reference standard. Analyses were carried out in triplicate and the results were expressed as $\mathrm{g}$ of compound/100 $\mathrm{g}$ of extract. 


\section{Quenching of DPPH}

The free radical-scavenging capacity of different concentrations of PE extract (3.4-1.7-0.85-0.56-0.42-0.34-0.21-0.17-0.11$0.085-0.028 \mathrm{mg} / \mathrm{ml}$ ) was measured by 2,2-diphenyl-1-picrylhydrazyl-hydrate (DPPH)-free radical method as previously reported (Salerno et al., 2012). Results are expressed as percentage of inhibition rate $\pm S D$.

\section{Scavenger Effect on Superoxide Anion}

The superoxide anion-scavenging capacity of different concentrations of PE extract (3.4-1.7-0.85-0.56-0.42-0.34$0.21-0.17-0.11-0.085-0.028 \mathrm{mg} / \mathrm{ml}$ ) was measured as previously reported (Salerno et al., 2012). Results are expressed as percentage of inhibition rate $\pm S D$.

\section{T3-L1 Murine Pre-adipocytes Cell Viability}

3T3-L1 murine pre-adipocytes were bought from American Type Culture Collection (Rockville, MD, United States). Cells were plated at a concentration of $2 \times 10^{5}$ cells per well of a 96-well microplate and cultured at $37^{\circ} \mathrm{C}$ in incubator with $5 \% \mathrm{CO}_{2}$ for $48 \mathrm{~h}$ in the absence and presence of the different concentrations of PE reported above. Cell viability was measured by MTT assay as previously reported (Di Giacomo et al., 2015). MTT, a yellow tetrazole, is reduced to purple formazan in living cells. Results are expressed as percentage of formazan produced in treated 3T3-L1 murine pre-adipocytes cells compared to untreated cells.

\section{Microbiology \\ Bacterial Cultivation}

The commercial pathogen strains E. coli ATCC 25922, S. aureus ATCC 29213, Listeria innocua ATCC 33090, and Salmonella enterica ATCC 14028 were used. E. coli strain was grown in Luria-Bertani (LB) broth at $37^{\circ} \mathrm{C}$ overnight; S. aureus, S. enterica, and $L$. innocua were routinely grown overnight, in Tryptone Soya Broth (TSB) at 37 and $30^{\circ} \mathrm{C}$, respectively. All media and supplements were provided by Oxoid (Milan, Italy).

The commercial probiotic strains LGG, Bifidobacterium animalis BB12, B. longum BB536, and the wild strain Lactobacillus paracasei N 24, isolated from Pecorino crotonese cheese, were cultured in deMan-Rogosa-Sharpe (MRS) broth at $37^{\circ} \mathrm{C}$ overnight.

Overnight bacterial culture was incubated at $37^{\circ} \mathrm{C}$ for $24 \mathrm{~h}$, under anaerobic condition, until they reached a cell density of approximately $1.0 \times 10^{9} \mathrm{cfu} / \mathrm{ml}$.

\section{Growth Rate Determination}

Based on results obtained on free radical scavenger activity of PE and on 3T3-L1 murine pre-adipocytes cell viability experiments, different concentrations were used for treatment of probiotic or pathogen strains as described below.

Antimicrobial activity of the PE was evaluated against the commercial pathogen strains mentioned above. Overnight pathogen cultures were co-cultured at $37^{\circ} \mathrm{C}$ for $24 \mathrm{~h}$ with $\mathrm{PE}$ at different concentrations $(1.7-0.34-0.17 \mathrm{mg} / \mathrm{ml})$, and the antimicrobial activity was evaluated by plating count of live bacteria and expressed as cfu/ml.

The effect of PE on the growth of probiotic strains mentioned above was evaluated inoculating in co-culture the probiotic strains at a cell density of approximately $1.0 \times 10^{9} \mathrm{cfu} / \mathrm{ml}$ with the $\mathrm{PE}$ at different concentrations $(0.085-0.042-0.028 \mathrm{mg} / \mathrm{ml})$. The effect of the extract on growth of probiotic strains was evaluated after incubation at $37^{\circ} \mathrm{C}$ for $24 \mathrm{~h}$ under anaerobic conditions by plating count of live bacteria and expressed as $\mathrm{cfu} / \mathrm{ml}$.

All experiment was conducted in duplicate and results were expressed as mean values and standard deviation. Based on preliminary results LGG was chosen for the subsequent analyses.

Fresh broth cultures were centrifuged at $5000 \mathrm{rpm}$ for $10 \mathrm{~min}$ at $4^{\circ} \mathrm{C}$, and the supernatant was decanted to collect the spent broth (SB), which was filtered (FSB), using a $0.22-\mu \mathrm{m}$ filter and then used for further analyses.

The bacterial pellet was resuspended in $1 \mathrm{ml}$ of PBS and sonicated five times at $44 \%$ amplitude for 2 min with 6 min of rest. The sonicate was then centrifuged at $1100 \times g$ for $15 \mathrm{~min}$ at $4^{\circ} \mathrm{C}$. The supernatant was collected, filtered through a $0.22-\mu \mathrm{m}$ filter, and labeled bacterial cell extract (CE). The CE was used for further analysis.

\section{Cell Culture and Adipocyte Cell Differentiation}

3T3-L1 murine pre-adipocytes were resuspended in Dulbecco's Modified Eagle Medium (DMEM), containing 10\% fetal bovine serum (FBS, Invitrogen, Carlsbad, CA, United States) and $1 \%$ antibiotic/antimycotic solution (Invitrogen, Carlsbad, CA, United States) and seeded in a $75-\mathrm{cm}^{2}$ flask at a density of 1 to $2 \times 10^{4}$ cells. Adipocyte cell differentiation was obtained as previously reported (Waldman et al., 2016).

Differentiating 3T3-L1 pre-adipocytes were treated for 7 days with PE $(0.028 \mathrm{mg} / \mathrm{ml})$, LGG CE $(25 \mu \mathrm{g} / \mathrm{ml})$, and LGG filtered SB $(10 \mu \mathrm{g} / \mathrm{ml})$ from overnight bacterial culture incubated with or without PE $(0.028 \mathrm{mg} / \mathrm{ml})$.

\section{Lipid Content Quantification}

To quantify lipid accumulation, Oil Red Staining was performed as previously reported (Barbagallo et al., 2017). Formation of lipid drops was measured with an inverted multichannel LED fluorescence microscope (Evos, Life Technologies, Grand Island, NY, United States).

\section{RNA Extraction and qRT-PCR}

Expressions of adiponectin, PPAR- $\gamma$, SREBP, FAS, IL-6, and IL-10 were evaluated by real-time PCR. RNA was extracted and quantified as previously reported (Raffaele et al., 2018). Appropriate primer sequences were used (Table 1). The relative mRNA expression level was measured by the threshold cycle (Ct) value of each PCR product and normalized with that of GAPDH by using comparative $2^{-\Delta \Delta \mathrm{Ct}}$ method.

\section{Statistical Analyses}

Statistical analyses of multiple comparisons were performed by the Fisher method. $P$-values lower than 0.05 were accepted as 
TABLE 1 | PCR primers used in this study.

\begin{tabular}{lll}
\hline Gene & Forward primer & Reverse primer \\
\hline Adiponectin & GAAGCCGCTTATGTGTATCGC & GAATGGGTACATTGGGAACAGT \\
IL-6 & TTCCTCTCTGCAAGAGACTTCC & AGGAGAGCATTGGAATTGGGG \\
FAS & GGAGGTGGTGATAGCCGGTAT & TGGGTAATCCATAGAGCCCAG \\
GAPDH & AGCTTCGGCACATATTCATCTG & CGTTCACTCCCATGACAAACA \\
IL-10 & GCTGGACAACATACTGCTAACC & ATTCCGATAAGGCTTGGCAA \\
SREBP-1 & GATGTGCGACTGGACACAG & CATAGGGGGCGTCAAACAG \\
PPAR- $\gamma$ & TCGCTGATGCACTGCCTATG & ACCTGATGGCATTGTGAGACAT
\end{tabular}

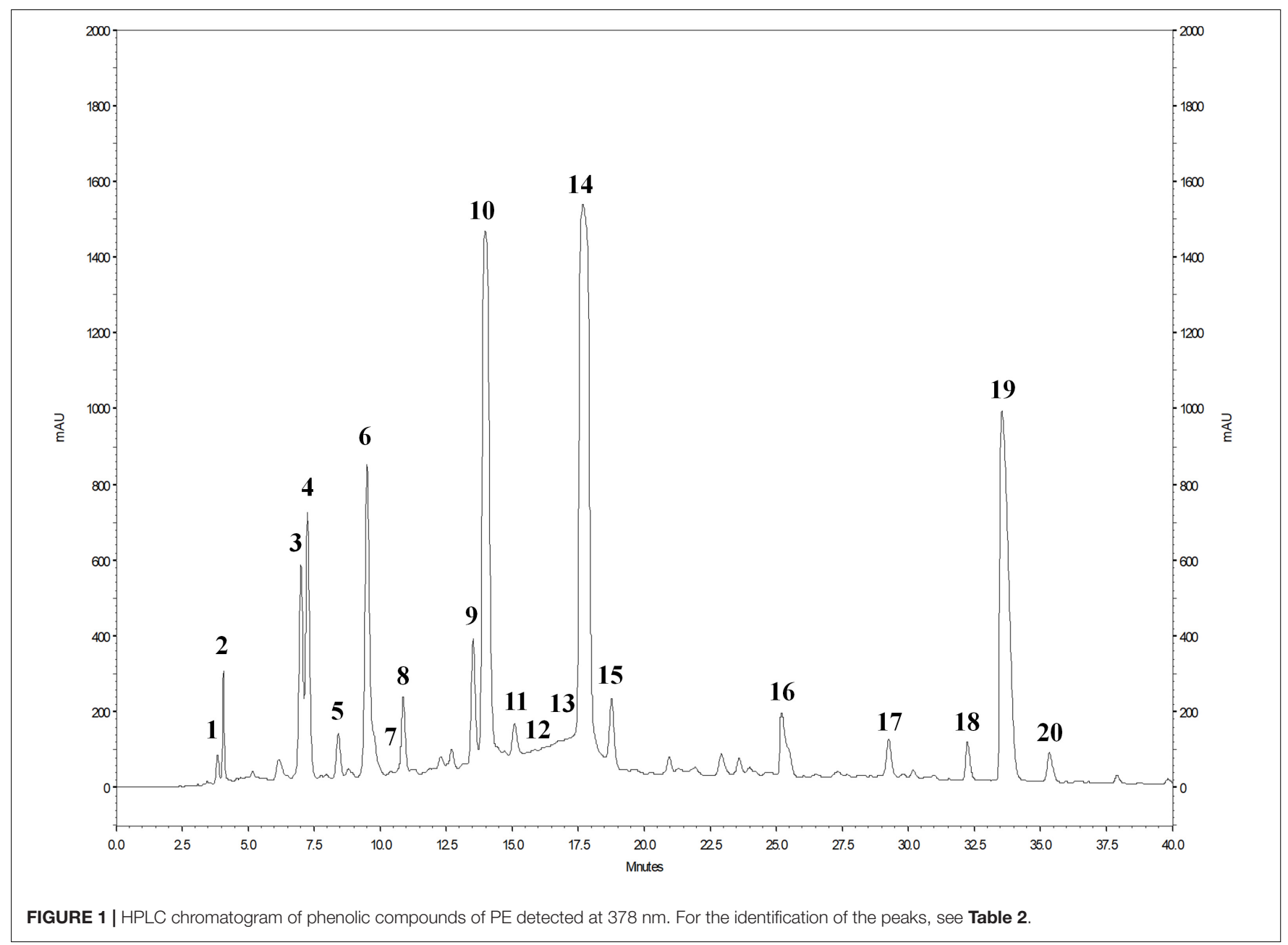

significant. Data were analyzed using either single-factor analysis of variance (ANOVA) for multiple groups, or the unpaired $t$-test for two groups, and the results are presented as mean \pm SD.

\section{RESULTS}

\section{HPLC-PDA-ESI/MS ${ }^{n}$ Analysis of PE}

The phenolic profile of PE (Figure 1) included the determination of 1 hydroxybenzoic acid and 19 ellagitannins. The main peaks corresponded to punicalin (peak 4), granatin B (peak 6), punicalagin A and B (peaks 10 and 14), and ellagic acid (peak
19) (Figure 1). The presence of gallic acid (peak 1) and ellagic acid derivatives (peaks 2, 3, 5, 7-9, 11-13, 15-18, and 20) was also revealed. As shown in the chromatogram, ellagitannins are the predominant class of phenolic compounds in pomegranate peel and marc (a by-product made up of seeds and peels), since they represent over the $99 \%$ of the total content of pomegranate phenolics. Punicalagins, the major ellagitannins of pomegranate by-products, accounted for $47.6 \%$ of the total phenolics content in PE (Table 2). Ellagic acid derivatives, ellagic acid, and other minor phenolic compounds (punicalin, granatin $\mathrm{B}$, and gallic acid), accounted for $38.4,10.2$, and $3.8 \%$ of the total phenolics content in PE, respectively (Table 2). 
TABLE 2 | Peak list and quantification of the phenolics in PE.

\begin{tabular}{|c|c|c|c|c|c|c|}
\hline Peak number ${ }^{a}$ & $\begin{array}{c}\text { RT } \\
(\min )\end{array}$ & $\begin{array}{l}\lambda_{\max } \\
(\mathrm{nm})\end{array}$ & $\begin{array}{r}{[\mathrm{M}-\mathrm{H}]^{-}} \\
(m / z)\end{array}$ & $\begin{array}{l}M^{n} \\
(m / z)\end{array}$ & $\begin{array}{l}\text { Phenolic } \\
\text { compounds }\end{array}$ & $\begin{array}{c}g / 100 \\
g^{b}\end{array}$ \\
\hline 1 & 3.9 & 269,310 & 169 & 125 & Gallic acid & $0.07 \pm 0.02$ \\
\hline 2 & 4.1 & 255,364 & - & 301 & Ead $^{d}$ & $0.03 \pm 0.01$ \\
\hline 3 & 7.0 & 255,363 & - & 301 & $\mathrm{Ead}^{\mathrm{d}}$ & $0.41 \pm 0.04$ \\
\hline 4 & 7.3 & 263,364 & 781 & 601 & Punicalin & $0.27 \pm 0.04$ \\
\hline 5 & 8.4 & 264,366 & - & 301 & $\mathrm{Ead}^{\mathrm{d}}$ & $0.19 \pm 0.09$ \\
\hline 6 & 9.5 & 260,365 & 951 & $933 / 613$ & Granatin B & $0.28 \pm 0.03$ \\
\hline 7 & 10.4 & 259,361 & - & 301 & $\mathrm{Ead}^{\mathrm{d}}$ & $0.02 \pm 0.01$ \\
\hline 8 & 10.9 & 257,360 & - & 301 & $\mathrm{Ead}^{\mathrm{d}}$ & $0.05 \pm 0.01$ \\
\hline 9 & 13.5 & 256,362 & - & 301 & Ead $^{d}$ & $1.23 \pm 0.04$ \\
\hline 10 & 14.0 & 258,378 & 1083 & $781 / 601$ & Punicalagin A & $3.05 \pm 0.05$ \\
\hline 11 & 15.1 & 257,363 & - & 301 & $\mathrm{Ead}^{\mathrm{d}}$ & $0.13 \pm 0.09$ \\
\hline 12 & 15.9 & 257,361 & - & 301 & $\mathrm{Ead}^{\mathrm{d}}$ & $0.95 \pm 0.03$ \\
\hline 13 & 16.8 & 258,360 & - & 301 & $\mathrm{Ead}^{\mathrm{d}}$ & $2.69 \pm 0.11$ \\
\hline 14 & 17.7 & 257,378 & 1083 & $781 / 601$ & Punicalagin B & $4.77 \pm 0.21$ \\
\hline 15 & 18.8 & 257,362 & - & 301 & $\mathrm{Ead}^{\mathrm{d}}$ & $0.12 \pm 0.01$ \\
\hline 16 & 25.2 & 256,363 & - & 301 & $\mathrm{Ead}^{\mathrm{d}}$ & $0.17 \pm 0.09$ \\
\hline 17 & 29.3 & 254,361 & - & 301 & $\mathrm{Ead}^{\mathrm{d}}$ & $0.17 \pm 0.01$ \\
\hline 18 & 32.2 & 255,360 & - & 301 & Ead $^{d}$ & $0.08 \pm 0.03$ \\
\hline 19 & 33.6 & 256,367 & 301 & $229 / 185$ & Ellagic acid & $1.68 \pm 0.01$ \\
\hline 20 & 35.4 & 248,362 & - & 301 & Ead $^{d}$ & $0.08 \pm 0.02$ \\
\hline Total polyphenols ${ }^{\mathrm{C}}$ & & & & & & $16.48 \pm 2.49$ \\
\hline Punicalagins & & & & & & 7.82 \\
\hline Ellagic acid derivatives & & & & & & 6.31 \\
\hline Ellagic acid & & & & & & 1.68 \\
\hline Other phenolic compounds & & & & & & 0.62 \\
\hline Total & & & & & & 16.43 \\
\hline
\end{tabular}

a The numbering is according to Figure 1. ${ }^{b}$ Results are expressed as the mean \pm standard deviation. ${ }^{c}$ Expressed as $g$ GAE/100 g. ${ }^{d}$ Ellagic acid derivative (Ead).

The mass spectrometric properties of the 20 phenolic compounds identified (peaks 1-20) are shown in Table 2. As previously reported (Romeo et al., 2015), two isomeric forms (A and B) of punicalagins (peaks 10 and 14) were observed, as well as the presence of granatin B (peak 6) was highlighted. Furthermore, these compounds were also characterized by direct infusion-negative ion ESI/MS ${ }^{n}$ analysis of standard compounds. Peak 4 was identified as punicalin $(m / z 781)$ while peaks $2,3,5,7-$ $9,11-13,15-18$, and 20 were identified as ellagic acid derivatives according to their UV-Vis and mass characteristics $\left(\lambda_{\max }\right.$ around $370 \mathrm{~nm}$ and $\mathrm{MS}^{1}$ fragment at $\mathrm{m} / z 301$ corresponding to ellagic acid).

\section{Free Radical Scavenging Activity of PE}

Antioxidant activity of PE was tested by their ability to reduce the stable DPPH radical.

Particularly, the percentage of inhibition of DPPH resulted up to $75 \%$ at concentrations lower to $0.21 \mathrm{mg} / \mathrm{ml}(76,78,79$, and $80 \%$ respectively, at concentration of PE of 0.17- 0.11- 0.085and $0.028 \mathrm{mg} / \mathrm{ml}$ ). At concentrations higher to $0.21 \mathrm{mg} / \mathrm{ml}$ the percentage of inhibition of DPPH resulted lower (Figure 2).

Pomegranate extract inhibited superoxide anion formation in a dose-dependent manner (Table 3). As a general trend, in this test $\mathrm{PE}$ resulted more effective than in the previous one. This might be due to the smaller size of superoxide anion compared to $\mathrm{DPPH}$ radical.

\section{Effect of PE on 3T3-L1 Cell Viability}

3-(4,5-Dimethylthiazol-2-yl)-2,5-Diphenyltetrazolium Bromide (MTT) assay was carried out to evaluate 3T3-L1 cell viability. Results show a significant reduction of cell viability with high concentrations of $\mathrm{PE}(3.4,1.7,0.85,0.56$, and $0.42 \mathrm{mg} / \mathrm{ml})$, whereas lower $(0.34,0.21,0.17,0.11$, and $0.085 \mathrm{mg} / \mathrm{ml})$ concentrations had a moderate inhibitory effect and $0.028 \mathrm{mg} / \mathrm{ml}$ concentration had no significant effect on 3T3-L1 murine preadipocytes cell viability (Figure 3 ).

\section{Microbiology}

\section{Antimicrobial Activity of the PE on Pathogen Strains}

Data of co-culture assay have shown that pathogens were differently sensitive to the PE. In detail, as showed in Figure 4, the extract at the concentration of $1.7 \mathrm{mg} / \mathrm{ml}$ showed the highest antimicrobial activity against all pathogens, with a significant decrease of L. innocua (proximally 4 log unit). At the concentration of $0.34 \mathrm{mg} / \mathrm{ml}$ the extract was efficacy against E. coli, L. innocua, and S. aureus, exhibiting a reduction of cell density of 1 and $2 \log$ units, respectively. When the PE was tested at $0.17 \mathrm{mg} / \mathrm{ml}$ concentration, S. aureus, S. enterica, and L. innocua 


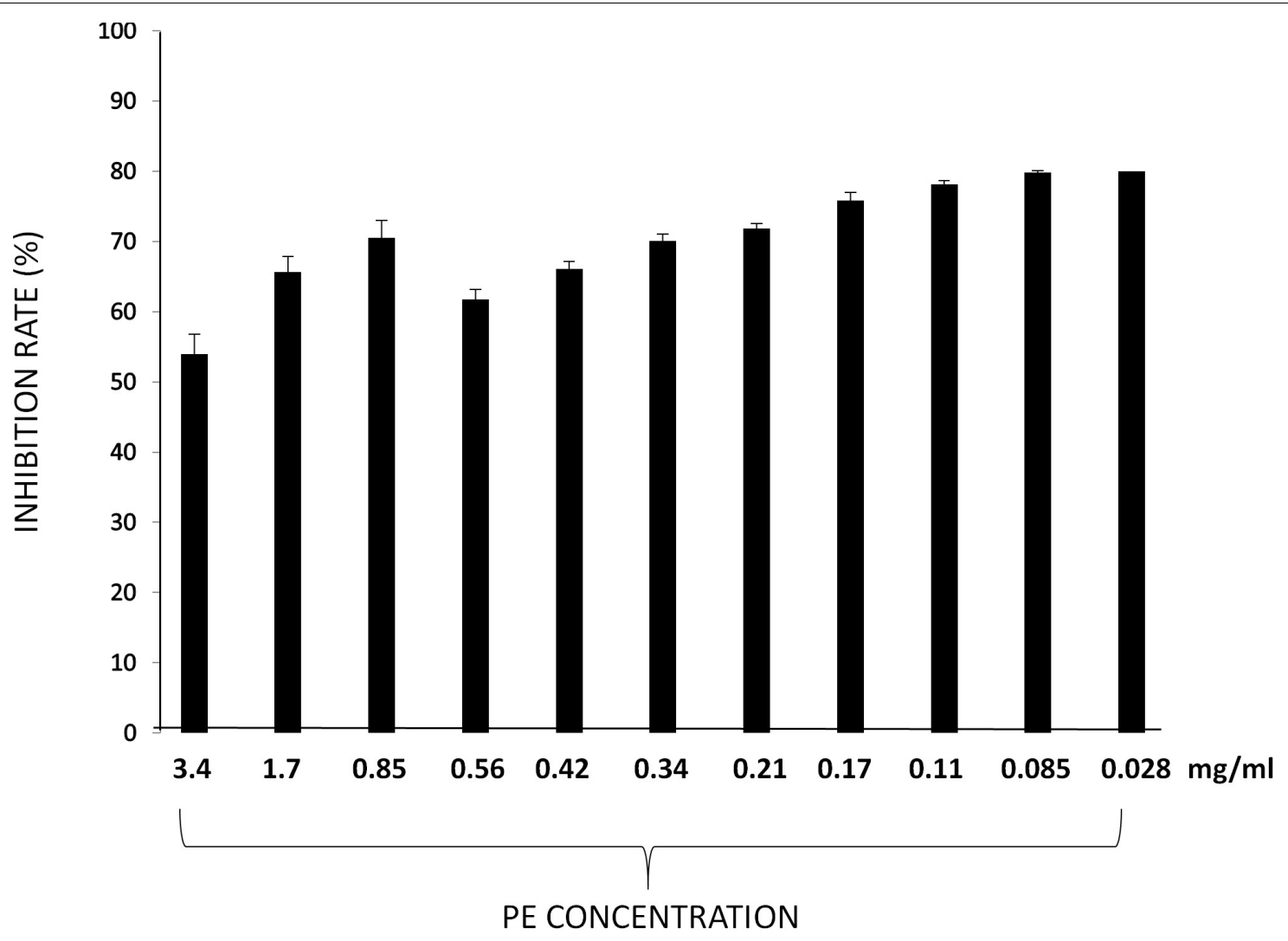

FIGURE 2 | DPPH radical scavenging activities of PE at different concentrations. Results are expressed as percentage of inhibition rate \pm SD.

TABLE 3 | Superoxide ion scavenging activities of different concentrations of PE.

\begin{tabular}{|c|c|c|c|}
\hline $\begin{array}{l}\text { PE } \\
\text { concentrations }\end{array}$ & $\begin{array}{c}\% \text { of } \\
\text { inhibition }\end{array}$ & PE concentrations & $\begin{array}{c}\% \text { of } \\
\text { inhibition }\end{array}$ \\
\hline PE (3.4 mg/ml) & $65 \pm 2$ & PE (0.21 mg/ml) & $78 \pm 2$ \\
\hline $\mathrm{PE}(1.7 \mathrm{mg} / \mathrm{ml})$ & $73 \pm 3$ & $\mathrm{PE}(0.17 \mathrm{mg} / \mathrm{ml})$ & $80 \pm 1$ \\
\hline $\mathrm{PE}(0.85 \mathrm{mg} / \mathrm{ml})$ & $75 \pm 1$ & $\mathrm{PE}(0.11 \mathrm{mg} / \mathrm{ml})$ & $85 \pm 3$ \\
\hline $\mathrm{PE}(0.56 \mathrm{mg} / \mathrm{ml})$ & $70 \pm 2$ & $\mathrm{PE}(0.085 \mathrm{mg} / \mathrm{ml}$ & $88 \pm 4$ \\
\hline $\mathrm{PE}(0.42 \mathrm{mg} / \mathrm{ml})$ & $68 \pm 1$ & $\mathrm{PE}(0.028 \mathrm{mg} / \mathrm{ml})$ & $95 \pm 1$ \\
\hline $\mathrm{PE}(0.34$ mg/ml) & $75 \pm 4$ & & \\
\hline
\end{tabular}

Results are expressed as percentage of inhibition rate $+S D$.

strains were still inhibited, while the growth of $E$. coli was not significantly affected.

\section{Effect of the PE on Growth of Probiotic Strains}

Results shown in Table 4 highlighted that PE, at all tested concentrations, did not have any inhibitory activity on growth of probiotic strains tested. A slight increase in growth was observed for LGG co-cultured with $\mathrm{PE}$ at concentration of $0.028 \mathrm{mg} / \mathrm{ml}$ (Table 4).

\section{Effect of PE on Lipid Content}

Pomegranate extract- and LGG-filtered SB significantly decreased the triglyceride content compared with the control group (Figures 5A,B). However, the effect of filtered SB derived from cells incubated with PE (LGG-T1) or without (LGG-T0) was similar. The simultaneous treatment of 3T3-L1 murine pre-adipocytes with PE- and LGG-filtered SB significantly decreased the triglyceride content compared with the treatment of LGG-filtered SB alone. Moreover, these data evidenced that combination treatment of PE and LGG-T1 was the most effective in reducing triglyceride content and intracellular lipid accumulation.

The treatment of 3T3-L1 murine pre-adipocytes with LGG cellular extract (CE), derived from cells incubated with PE $(\mathrm{CE}+\mathrm{PE})$ or without $(\mathrm{CE})$, had no effect on intracellular lipid accumulation compared with the control group (Control: ABS $490 \mathrm{~nm}=0.200 \pm 0.07$; CE: ABS $490 \mathrm{~nm}=0.187 \pm 0.09$; $\mathrm{CE}+\mathrm{PE}=\mathrm{ABS} 490 \mathrm{~nm}=0.190 \pm 0.05)$.

\section{Effect of PE on Adipogenic Markers}

The mRNA expression levels of the main transcriptional factors involved in adipocyte differentiation were significantly less expressed in 3T3-L1 cells treated with PE- and LGG-filtered SB. Particularly PE, LGG-T0, and LGG-T1 were able to decrease gene levels of Adiponectin, PPAR- $\gamma$, SREBP, FAS, and IL- 6 and to increase gene levels of IL-10 (Figures 6A-F).

The simultaneous treatment of 3T3-L1 murine pre-adipocytes with PE- and LGG-filtered SB (LGGT0 and LGGT1) significantly decreased mRNA expression levels of the main transcriptional 


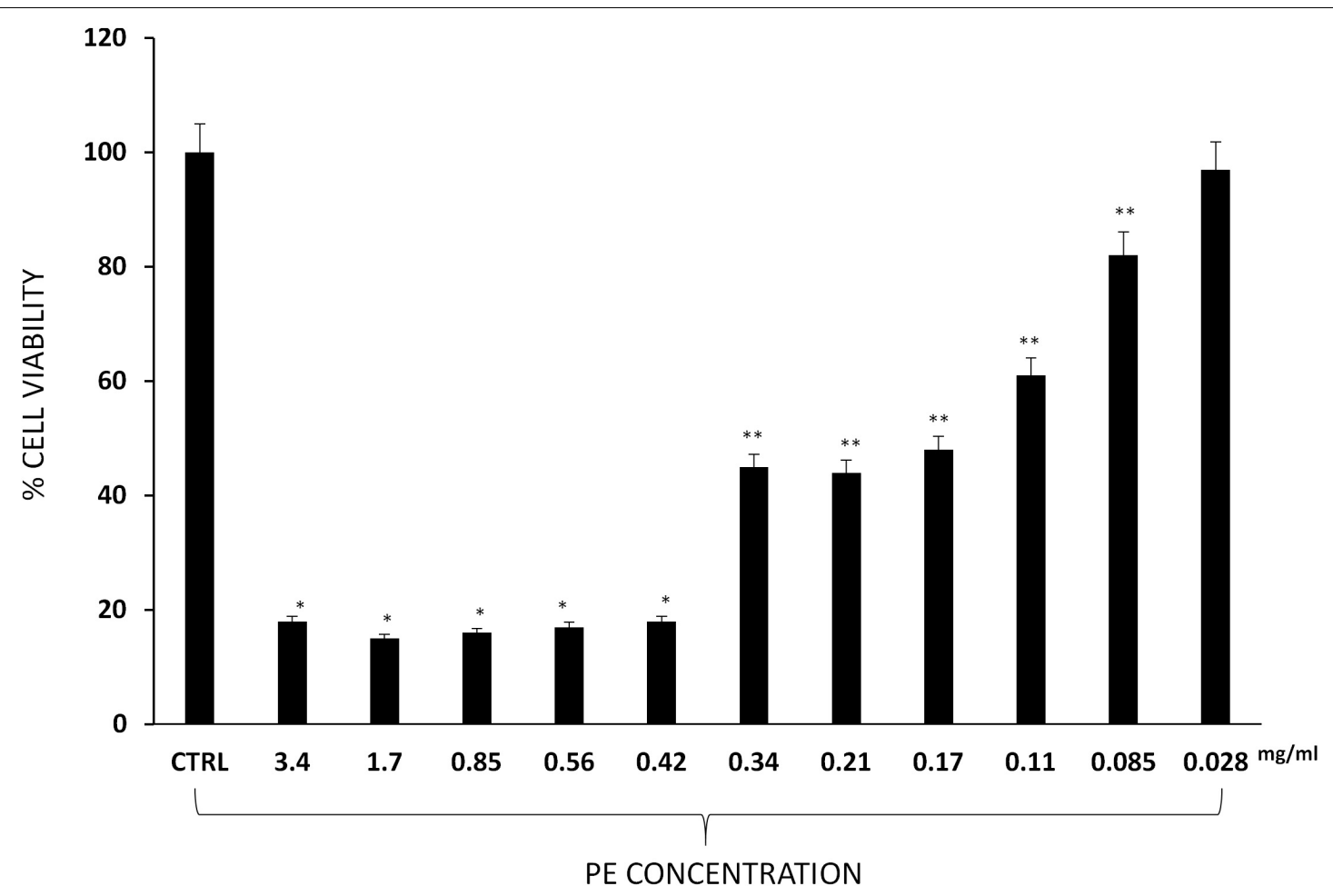

FIGURE 3 | Percentage of 3T3-L1 murine pre-adipocytes survival in the presence of PE at different concentrations. Results are expressed as the means $\pm \mathrm{SD}$ of four experiments performed in triplicate. Significant vs. untreated controls: ${ }^{*} p<0.005 ;{ }^{* *} p<0.05$

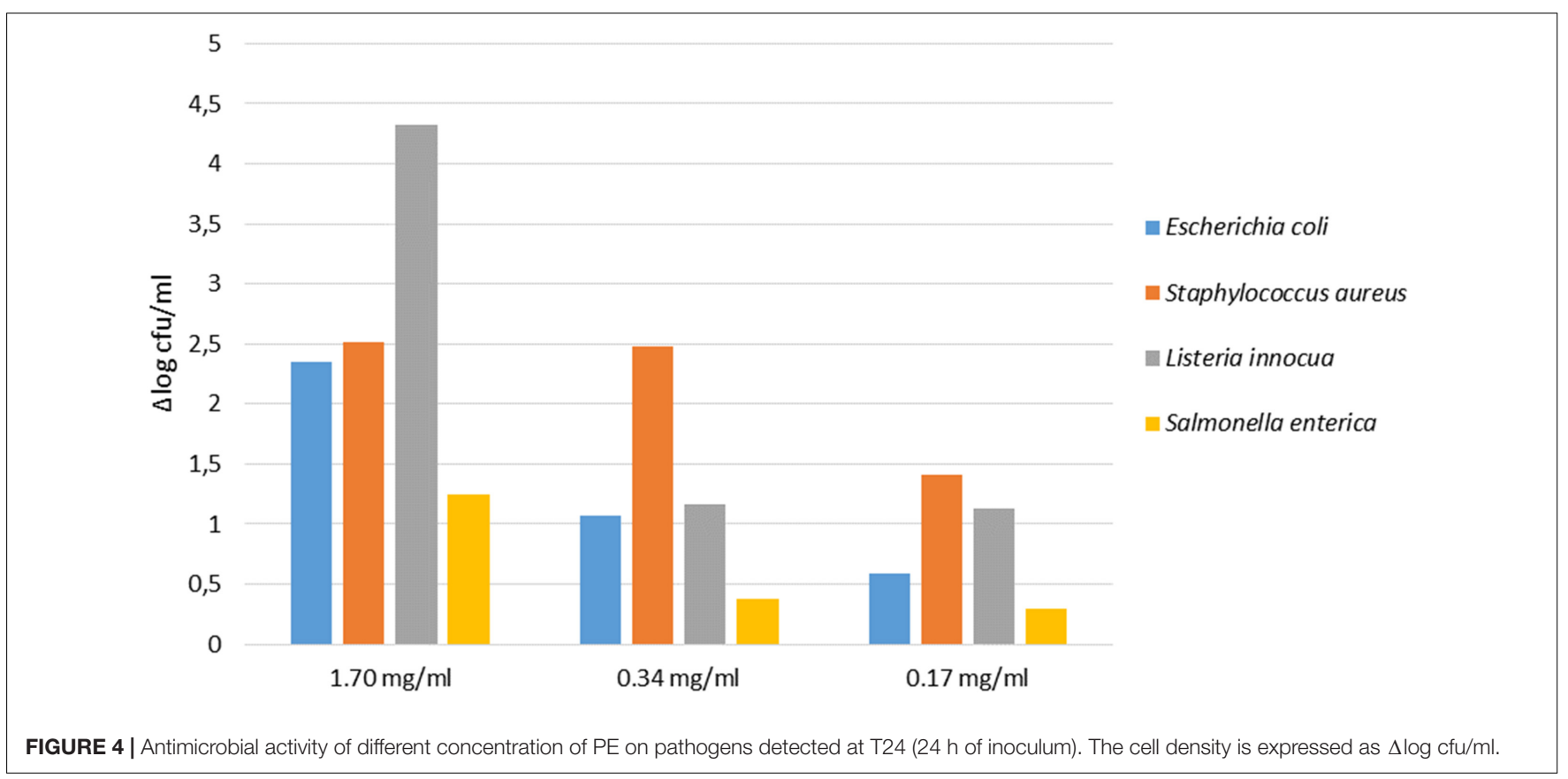

factors involved in adipogenesis, compared with the treatment of LGG-filtered SB (LGGT0 and LGGT1) alone (Figures 6A-E).

The simultaneous treatment of 3T3-L1 murine pre-adipocytes with PE- and LGG-filtered SB (LGGT0 and LGGT1) significantly increased mRNA expression levels of IL10, compared with the treatment of LGG-filtered SB (LGGT0 and LGGT1) alone (Figure 6F). Moreover, these data evidenced that combination treatment of PE+LGG T1 was the most effective in reducing mRNA expression levels of Adiponectin, IL-6, FAS, and in upregulating IL-10 (Figures 6A,D-F). 
TABLE 4 | Bacterial counts expressed as $\log _{10} \mathrm{cfu} / \mathrm{ml}$ of three replicates $\pm \mathrm{SD}$ of L. rhamnosus GG ATCC 53103, Bifidobacterium animalis BB12, B. longum BB536, and the wild strain Lactobacillus paracasei N 24 after incubation with PE at different concentrations.

\begin{tabular}{lcc}
\hline & & Log $_{10}$ \\
\hline L. rhamnosus GG & Baseline & $8.83 \pm 0.09^{\mathrm{a}}$ \\
ATCC 53103 & PE $(0.085 \mathrm{mg} / \mathrm{ml})$ & $9.20 \pm 0.10^{\mathrm{b}}$ \\
& PE $(0.042 \mathrm{mg} / \mathrm{ml})$ & $9.24 \pm 0.07^{\mathrm{b}}$ \\
& PE $(0.028 \mathrm{mg} / \mathrm{ml})$ & $9.26 \pm 0.04^{\mathrm{b}}$ \\
Lactobacillus paracasei & Baseline & $8.65 \pm 0.15^{\mathrm{a}}$ \\
N24 & PE $(0.085 \mathrm{mg} / \mathrm{ml})$ & $8.70 \pm 0.08^{\mathrm{a}}$ \\
& PE $(0.042 \mathrm{mg} / \mathrm{ml})$ & $8.79 \pm 0.10^{\mathrm{a}}$ \\
Bifidobacterium animalis & PE $(0.028 \mathrm{mg} / \mathrm{ml})$ & $8.74 \pm 0.09^{\mathrm{a}}$ \\
BB12 & Baseline & $9.15 \pm 0.05^{\mathrm{a}}$ \\
& PE $(0.085 \mathrm{mg} / \mathrm{ml})$ & $9.15 \pm 0.12^{\mathrm{a}}$ \\
& PE $(0.042 \mathrm{mg} / \mathrm{ml})$ & $9.44 \pm 0.10^{\mathrm{b}}$ \\
B. longum & PE $(0.028 \mathrm{mg} / \mathrm{ml})$ & $9.55 \pm 0.07^{\mathrm{b}}$ \\
BB536 & Baseline & $9.77 \pm 0.03^{\mathrm{a}}$ \\
& PE $(0.085 \mathrm{mg} / \mathrm{ml})$ & $9.54 \pm 0.10^{\mathrm{a}}$ \\
& PE $(0.042 \mathrm{mg} / \mathrm{ml})$ & $9.57 \pm 0.12^{\mathrm{a}}$ \\
& PE $(0.028 \mathrm{mg} / \mathrm{ml})$ & $9.44 \pm 0.16^{\mathrm{a}}$ \\
\hline
\end{tabular}

\section{DISCUSSION}

The beneficial effects of pomegranate fruit and/or juice consumption have received considerable scientific interest (Basu and Penugonda, 2009). Many investigators have reported that PEs, made from a waste product of the processing factories, have a free radical scavenging and potent antioxidant capacity (Panichayupakaranant et al., 2010; Fischer et al., 2011). PE used in the present study was soluble in water, and characterized through HPLC-PDA-ESI/MS ${ }^{\mathrm{n}}$ for its phenolic and anthocyanin content. In agreement with previous reports (Fischer et al., 2011; Qu et al., 2012; Romeo et al., 2015), ellagitannins are the predominant class of phenolic compounds in pomegranate peel and marc (a by-product made up of seeds and peels), since they represent over the $99 \%$ of the total content of pomegranate phenolics. The major ellagitannins of pomegranate by-products, as well as pomegranate products (fruit and juice), are punicalagins (Gil et al., 2000; Fischer et al., 2011; Qu et al., 2012).

Pomegranate extract contains high percentages of phenolic compounds and showed antioxidant activities in a concentrationdependent manner as shown for both the DPPH and superoxide anion scavenging assay.

It has been reported that dietary plant polyphenols are able to selectively modulate the growth of susceptible microorganisms (Tabasco et al., 2011). Plant extracts commonly inhibit bacterial growth, but the magnitude of the effect depends on the composition of the extract and the type of bacterial strain.

Results obtained in our experimental conditions demonstrated that high concentrations of pomegranate polyphenols exert antimicrobial activity on some pathogen strains such as L. innocua and S. aureus. These results are in agreement with studies of Panichayupakaranant et al. (2010), Fawole et al. (2012), and Su et al. (2012).
However, at concentrations of PE lower to $0.34 \mathrm{mg} / \mathrm{ml}$, although none inhibitory activity concentrations was detected against the probiotic strains, only a slight increase in growth of LGG was evaluated. These results are not in agreement with studies of Li et al. (2015) and of Neyrinck et al. (2013) that demonstrated that pomegranate polyphenols may potentially work as prebiotics.

Obesity is a condition in which the lipids have accumulated leading to expansion of the adipose tissue that acts as a metabolic and endocrine organ. The molecular mechanisms that modulate pre-adipocytes growth, differentiation, and lipogenesis of fat cells have been subjected to extensive studies (Vanella et al., 2012; Stechschulte et al., 2014; Moseti et al., 2016; Palmeri et al., 2016; Waldman et al., 2016; Carpene et al., 2018).

During adipocyte differentiation, preadipocytes differentiate into mature adipocytes (Lefterova and Lazar, 2009). Increased fat accumulation is strongly correlated with cell number and/or size of adipocytes (Jiang et al., 2008).

It has been reported that the degree of obesity is related to the differentiation of preadipocytes in adipocytes and with enlarged adipocytes in adipose tissues (Wang and Jones, 2004).

Other authors reported that PEs were able to suppress preadipocyte differentiation and adipogenesis and to ameliorate fatty liver in the rats with obesity and type 2 diabetes (Xu et al., 2009).

In agreement with data of Moon et al. (2012) and Park et al. (2014) in our experimental conditions PE, LGG-T0, and LGGT1 resulted in a significant reduction in lipid accumulation in 3T3-L1 cells during differentiation into adipocytes suggesting that PE, LGG-T0, and LGG-T1 are able to suppress adipocyte differentiation. However, the treatment with LGG-filtered SB derived from cells incubated with PE (LGG-T1) or without (LGG-T1) was similar. In our experimental conditions, in fact, it was not observed the prebiotic effect demonstrated by other authors. Moreover, the combination treatment of PE and LGG-T1 was the most effective in reducing intracellular lipid accumulation. These data demonstrate that, even if in our experimental conditions it was not observed a prebiotic effect, filtered SB obtained from LGG incubated with PE (LGGT1), might contain, besides the beneficial bacterial secreted bioactive compounds, also small amounts of PE-derived bioactive compounds. The latter, present in small amounts in LGG-T1, would not be able to exert higher beneficial effects than LGGT0, but in combination with PE could have potential synergistic health benefits.

Adipocyte-specific peroxisome proliferator-activated receptor- $\gamma(\operatorname{PPAR} \gamma)$ is involved in the early stage of adipocyte differentiation (Rosen et al., 2000) regulating the expression of adipogenic genes such as fatty acid synthase (FAS) and sterol regulatory element-binding proteins (SREBP) and then triggering the accumulation of fat in the cells (Kawada et al., 2001; Berger and Moller, 2002).

Adipose tissue is not only a primary fat reservoir, but it is also an endocrine organ which controls lipid homeostasis. Altered levels of adipose tissue-derived adipokines can contribute in developing of inflammation, resulting in impaired lipid metabolism (Armani et al., 2010). In chronic inflammation, 


\section{A}

CTRL

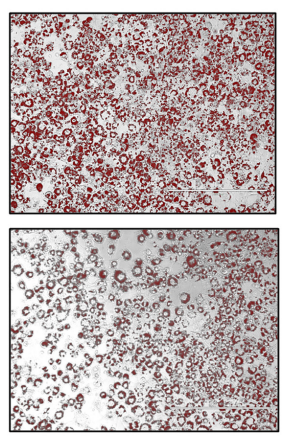

LGG TO + PE
LGG TO
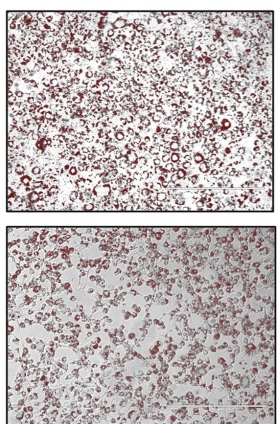

LGG T1 + PE
LGG T1

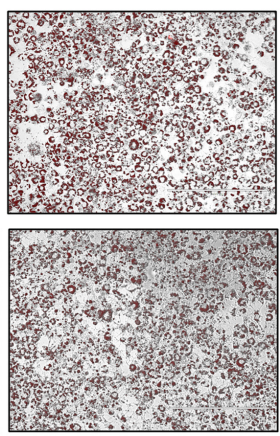

PE

B

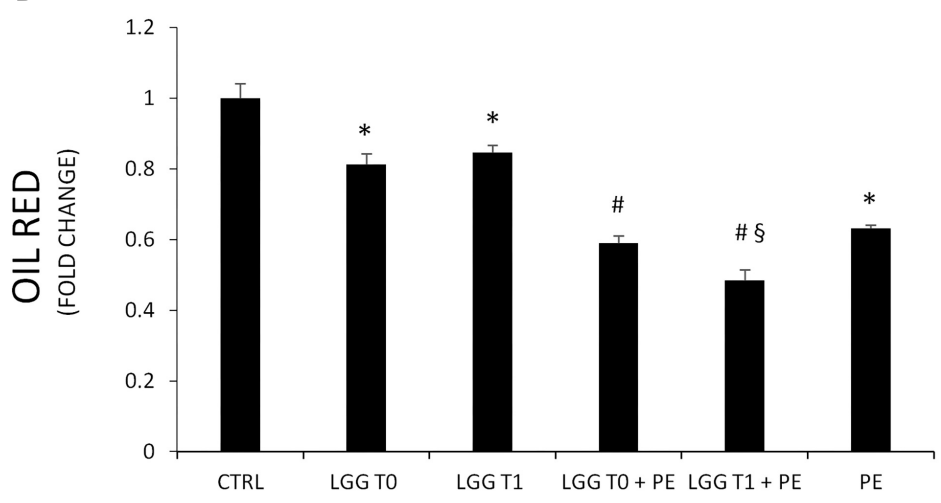

FIGURE 5 | (A) Representative Oil red O staining of 3T3-L1 cells in absence and in presence of PE, LGG TO, LGG T1, LGG TO + PE, and LGG T1 + PE. (B) Lipid content was quantified with Oil Red O staining (mean $\pm S D,{ }^{*} p<0.05$ versus control; ${ }^{\#} p<0.05$ versus LGG TO and LGG T1; ${ }^{\S} p<0.05$ versus LGG T0+PE).

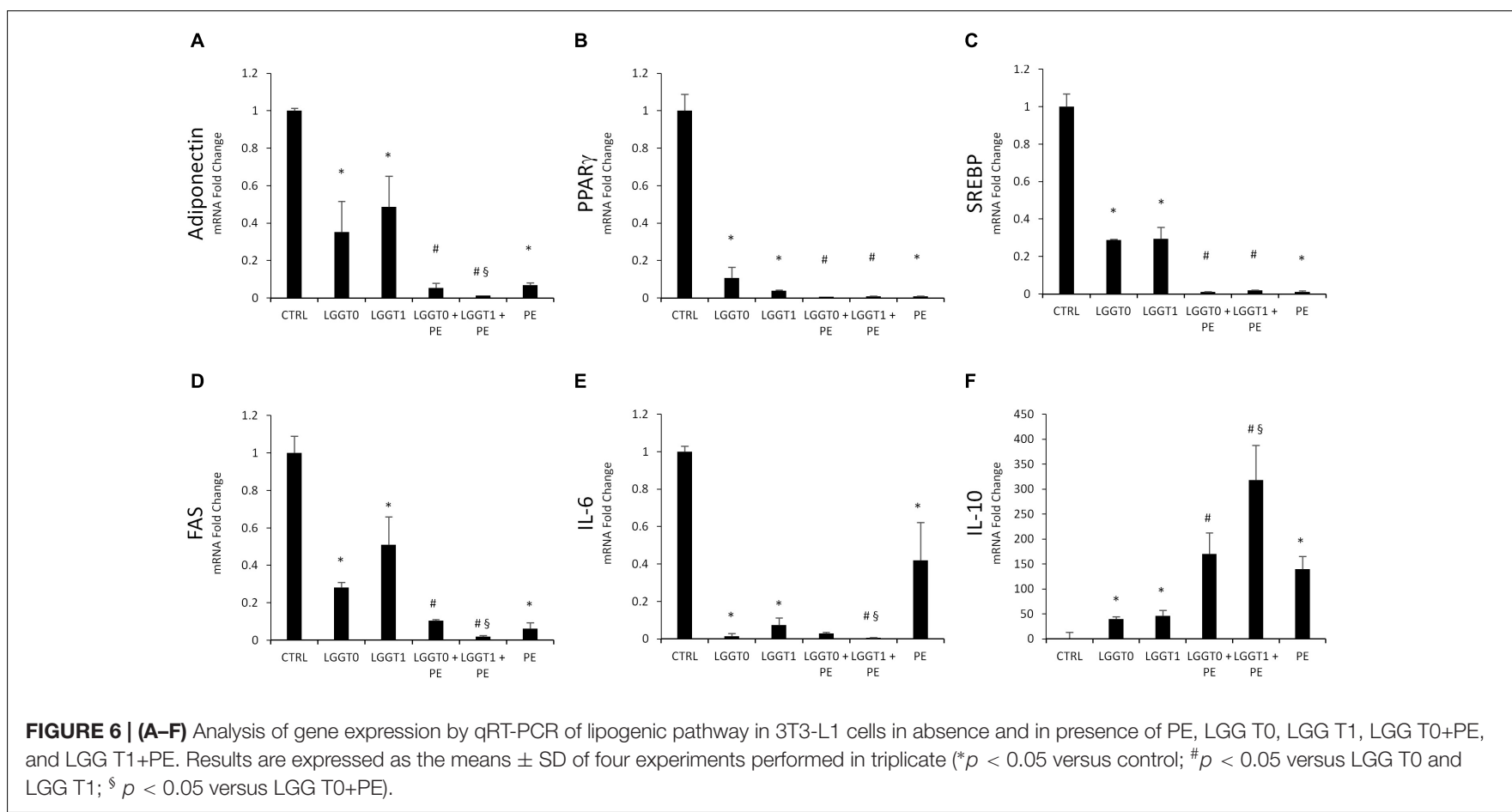


proinflammatory cytokines such as IL-6 are upregulated while antiflammatory cytokines such as IL-10 are downregulated (Kershaw and Flier, 2004; Bradley et al., 2008; Lira et al., 2012; Liu et al., 2018).

Our results demonstrate that the combination treatment with PE+LGG-T1 significantly downregulated the mRNA levels of adiponectin, FAS, and IL- 6 and upregulated IL- 10 .

We can conclude that the combination treatment with PE+LGG-T1 possesses anti-inflammatory properties and it is able to inhibit the adipocyte differentiation by modulating the expression levels of key adipogenic transcription factors involved in adipogenesis.

\section{CONCLUSION}

Pomegranate extract- and LGG-filtered SB significantly decreased intracellular lipid accumulation. A synergistic effect of probiotics and polyphenols contained in PE was

\section{REFERENCES}

Al-Zoreky, N. S. (2009). Antimicrobial activity of pomegranate (Punica granatum L.) fruit peels. Int. J. Food Microbiol. 134, 244-248. doi: 10.1016/j.ijfoodmicro. 2009.07.002

Armani, A., Mammi, C., Marzolla, V., Calanchini, M., Antelmi, A., Rosano, G. M., et al. (2010). Cellular models for understanding adipogenesis, adipose dysfunction, and obesity. J. Cell Biochem. 110, 564-572. doi: 10.1002/jcb.22598

Barbagallo, I., Li Volti, G., Sorrenti, V., Di Giacomo, C., Acquaviva, R., Raffaele, M., et al. (2017). Caffeic acid phenethyl ester restores adipocyte gene profile expression following lipopolysaccharide treatment. Lett. Drug Des. Discov. 14, 481-487. doi: 10.2174/1570180813666160901124707

Bassiri-Jahromi, S. (2018). Punica granatum (Pomegranate) activity in health promotion and cancer prevention. Oncol. Rev. 12:345. doi: 10.4081/oncol.20 18.345

Basu, A., and Penugonda, K. (2009). Pomegranate juice: a heart-healthy fruit juice. Nutr. Rev. 67, 49-56. doi: 10.1111/j.1753-4887.2008.00133.x

Berger, J., and Moller, D. E. (2002). The mechanisms of action of PPARs. Annu. Rev. Med. 53, 409-435. doi: 10.1146/annurev.med.53.082901.104018

Bialonska, D., Kasimsetty, S. G., Schrader, K. K., and Ferreira, D. (2009). The effect of pomegranate (Punica granatum L.) byproducts and ellagitannins on the growth of human gut bacteria. J. Agric. Food Chem. 57, 8344-8349. doi: 10.1021/jf901931b

Bialonska, D., Ramnani, P., Kasimsetty, S. G., Muntha, K. R., Gibson, G. R., and Ferreira, D. (2010). The influence of pomegranate by-product and punicalagins on selected groups of human intestinal microbiota. Int. J. Food Microbiol. 140, 175-182. doi: 10.1016/j.ijfoodmicro.2010.03.038

Bradley, R. L., Fisher, F. F., and Maratos-Flier, E. (2008). Dietary fatty acids differentially regulate production of TNF-alpha and IL-10 by murine 3T3-L1 adipocytes. Obesity 16, 938-944. doi: 10.1038/oby.2008.39

Carpene, C., Pejenaute, H., Del Moral, R., Boulet, N., Hijona, E., Andrade, F., et al. (2018). The dietary antioxidant piceatannol inhibits adipogenesis of human adipose mesenchymal stem cells and limits glucose transport and lipogenic activities in adipocytes. Int. J. Mol. Sci. 19:E2081. doi: 10.3390/ijms19072081

Dhumal, S. S., Karale, A. R., Jadhav, S. B., and Kad, V. P. (2014). Recent advances and the developments in the pomegranate processing and utilization: a review. J. Agric. Crop Sci. 1, 1-17.

Di Giacomo, C., Vanella, L., Sorrenti, V., Santangelo, R., Barbagallo, I., Calabrese, G., et al. (2015). Effects of tithonia diversifolia (Hemsl.) A. Gray extract on adipocyte differentiation of human mesenchymal stem cells. PLoS One 10:e0122320. doi: 10.1371/journal.pone.0122320

Fawole, O. A., Makunga, N. P., and Opara, U. L. (2012). Antibacterial, antioxidant and tyrosinase-inhibition activities of pomegranate fruit peel methanolic observed. Moreover, our results evidenced that combination treatment of PE+LGG T1 was the most effective in reducing mRNA expression levels of Adiponectin, IL-6, FAS, and in upregulating IL-10.

These results evidenced that probiotics and polyphenols contained in PE may affect adipogenesis in vitro. Moreover, our results demonstrate that the synergistic properties of combining foods such as pomegranate and probiotics may exert combined health benefits.

Then pomegranate and probiotics such as LGG strain may contribute in development of new nutraceutical/probiotic-based remedies to prevent and to treat obesity.

\section{AUTHOR CONTRIBUTIONS}

VS, LV, CR, CC, FR, and GB collected research articles, conceived the experiments, analyzed the results, and wrote the manuscript. $\mathrm{CR}, \mathrm{MR}, \mathrm{SF}$, and NT conducted the experiments.

extract. BMC Complement. Altern. Med. 12:200. doi: 10.1186/1472-688212-200

Fischer, U. A., Carle, R., and Kammerer, D. R. (2011). Identification and quantification of phenolic compounds from pomegranate (Punica granatum L.) peel, mesocarp, aril and differently produced juices by HPLC-DAD-ESI/MS(n). Food Chem. 127, 807-821. doi: 10.1016/j.foodchem.2010.12.156

Gil, M. I., Tomas-Barberan, F. A., Hess-Pierce, B., Holcroft, D. M., and Kader, A. A. (2000). Antioxidant activity of pomegranate juice and its relationship with phenolic composition and processing. J. Agric. Food Chem. 48, 4581-4589.

Hossin, F. L. A. (2009). Effect of pomegranate (Punica granatum) peels and it's extract on obese hypercholesterolemic rats. Pak. J. Nutr. 8, 1251-1257. doi: 10.3923/pjn.2009.1251.1257

Jiang, L., Zhang, N. X., Mo, W., Wan, R., Ma, C. G., Li, X., et al. (2008). Rehmannia inhibits adipocyte differentiation and adipogenesis. Biochem. Biophys. Res. Commun. 371, 185-190. doi: 10.1016/j.bbrc.2008.03.129

Kawada, T., Takahashi, N., and Fushiki, T. (2001). Biochemical and physiological characteristics of fat cell. J. Nutr. Sci. Vitaminol. 47, 1-12.

Kershaw, E. E., and Flier, J. S. (2004). Adipose tissue as an endocrine organ. J. Clin. Endocrinol. Metab. 89, 2548-2556. doi: 10.1210/jc.2004-0395

Kim, S. H., and Plutzky, J. (2016). Brown fat and browning for the treatment of obesity and related metabolic disorders. Diabetes Metab. J. 40, 12-21. doi: 10.4093/dmj.2016.40.1.12

Lai, C. S., Tsai, M. L., Badmaev, V., Jimenez, M., Ho, C. T., and Pan, M. H. (2012). Xanthigen suppresses preadipocyte differentiation and adipogenesis through down-regulation of PPARgamma and C/EBPs and modulation of SIRT-1, AMPK, and FoxO pathways. J. Agric. Food Chem. 60, 1094-1101. doi: $10.1021 /$ jf204862d

Lee, C. J., Chen, L. G., Liang, W. L., and Wang, C. C. (2010). Anti-inflammatory effects of punica granatum Linne in vitro and in vivo. Food Chem. 118, 315-322.

Lefterova, M. I., and Lazar, M. A. (2009). New developments in adipogenesis. Trends Endocrinol. Metab. 20, 107-114. doi: 10.1016/j.tem.2008.11.005

Les, F., Arbones-Mainar, J. M., Valero, M. S., and Lopez, V. (2018). Pomegranate polyphenols and urolithin A inhibit alpha-glucosidase, dipeptidyl peptidase4, lipase, triglyceride accumulation and adipogenesis related genes in 3T3-L1 adipocyte-like cells. J. Ethnopharmacol. 220, 67-74. doi: 10.1016/j.jep.2018. 03.029

Li, Y. F., Guo, C. J., Yang, J. J., Wei, J. Y., Xu, J., and Cheng, S. (2006). Evaluation of antioxidant properties of pomegranate peel extract in comparison with pomegranate pulp extract. Food Chem. 96, 254-260.

Li, Z., Summanen, P. H., Komoriya, T., Henning, S. M., Lee, R. P., Carlson, E., et al. (2015). Pomegranate ellagitannins stimulate growth of gut bacteria in vitro: implications for prebiotic and metabolic effects. Anaerobe 34, 164-168. doi: 10.1016/j.anaerobe.2015.05.012 
Lin, L. T., Chen, T. Y., Lin, S. C., Chung, C. Y., Lin, T. C., Wang, G. H., et al. (2013). Broad-spectrum antiviral activity of chebulagic acid and punicalagin against viruses that use glycosaminoglycans for entry. BMC Microbiol. 13:187. doi: 10.1186/1471-2180-13-187

Lira, F. S., Rosa, J. C., Pimentel, G. D., Seelaender, M., Damaso, A. R., Oyama, L. M., et al. (2012). Both adiponectin and interleukin-10 inhibit LPS-induced activation of the NF-kappaB pathway in 3T3-L1 adipocytes. Cytokine 57, 98-106. doi: 10.1016/j.cyto.2011.10.001

Liu, Y., Xu, D., Yin, C., Wang, S., Wang, M., and Xiao, Y. (2018). IL-10/STAT3 is reduced in childhood obesity with hypertriglyceridemia and is related to triglyceride level in diet-induced obese rats. BMC Endocr. Disord. 18:39. doi: 10.1186/s12902-018-0265-z

Moon, Y. J., Soh, J. R., Yu, J. J., Sohn, H. S., Cha, Y. S., and Oh, S. H. (2012). Intracellular lipid accumulation inhibitory effect of Weissella koreensis OK16 isolated from Kimchi on differentiating adipocyte. J. Appl. Microbiol. 113, 652-658. doi: 10.1111/j.1365-2672.2012.05348.x

Moseti, D., Regassa, A., and Kim, W. K. (2016). Molecular regulation of adipogenesis and potential anti-adipogenic bioactive molecules. Int. J. Mol. Sci. 17:E124. doi: 10.3390/ijms17010124

Neyrinck, A. M., Van Hee, V. F., Bindels, L. B., De Backer, F., Cani, P. D., and Delzenne, N. M. (2013). Polyphenol-rich extract of pomegranate peel alleviates tissue inflammation and hypercholesterolaemia in high-fat diet-induced obese mice: potential implication of the gut microbiota. Br. J. Nutr. 109, 802-809. doi: $10.1017 /$ S0007114512002206

Palmeri, R., Monteleone, J. I., Spagna, G., Restuccia, C., Raffaele, M., Vanella, L., et al. (2016). Olive leaf extract from sicilian cultivar reduced lipid accumulation by inducing thermogenic pathway during adipogenesis. Front. Pharmacol. 7:143. doi: 10.3389/fphar.2016.00143

Panichayupakaranant, P., Tewtrakul, S., and Yuenyongsawad, S. (2010). Antibacterial, anti-inflammatory and anti-allergic activities of standardised pomegranate rind extract. Food Chem. 123, 400-403. doi: 10.1055/s-00301264706

Park, J. E., Oh, S. H., and Cha, Y. S. (2014). Lactobacillus brevis OPK-3 isolated from kimchi inhibits adipogenesis and exerts anti-inflammation in 3T3-L1 adipocyte. J. Sci. Food Agric. 94, 2514-2520. doi: 10.1002/jsfa.6588

Qu, W., Breksa Iii, A. P., Pan, Z., and Ma, H. (2012). Quantitative determination of major polyphenol constituents in pomegranate products. Food Chem. 132, 1585-1591. doi: 10.1016/j.foodchem.2011.11.106

Raffaele, M., Barbagallo, I., Licari, M., Carota, G., Sferrazzo, G., Spampinato, M., et al. (2018). N-Acetylcysteine (NAC) ameliorates lipid-related metabolic dysfunction in bone marrow stromal cells-derived adipocytes. Evid. Based Complement. Altern. Med. 2018:9. doi: 10.1155/2018/5310961

Reddy, M. K., Gupta, S. K., Jacob, M. R., Khan, S. I., and Ferreira, D. (2007). Antioxidant, antimalarial and antimicrobial activities of tannin-rich fractions, ellagitannins and phenolic acids from Punica granatum L. Planta Med. 73, 461-467. doi: 10.1055/s-2007-967167

Romeo, F. V., Ballistreri, G., Fabroni, S., Pangallo, S., Nicosia, M. G., Schena, L., et al. (2015). Chemical characterization of different sumac and pomegranate extracts effective against botrytis cinerea rots. Molecules 20, 11941-11958. doi: 10.3390/molecules200711941

Rosen, E. D., Walkey, C. J., Puigserver, P., and Spiegelman, B. M. (2000). Transcriptional regulation of adipogenesis. Genes Dev. 14, 1293-1307.

Salerno, L., Modica, M. N., Romeo, G., Pittala, V., Siracusa, M. A., Amato, M. E., et al. (2012). Novel inhibitors of nitric oxide synthase with antioxidant properties. Eur. J. Med. Chem. 49, 118-126. doi: 10.1016/j.ejmech.2012. 01.002
Singleton, V. L., Orthofer, R., and Lamuela-Raventos, R. M. (1999). Analysis of total phenols and other oxidation substrates and antioxidants by means of Folin-Ciocalteau reagent. Methods Enzymol. 299, 152-178. doi: 10.1016/S00766879(99)99017-1

Smith, K. B., and Smith, M. S. (2016). Obesity Statistics. Prim Care 43, 121-135. doi: 10.1016/j.pop.2015.10.001

Stechschulte, L. A., Hinds, TD Jr, Khuder, S. S., Shou, W., Najjar, S. M., and Sanchez, E. R. (2014). FKBP51 controls cellular adipogenesis through p38 kinasemediated phosphorylation of GRalpha and PPARgamma. Mol. Endocrinol. 28, 1265-1275. doi: 10.1210/me.2014-1022

Su, X., Howell, A. B., and D'Souza, D. H. (2012). Antibacterial effects of plantderived extracts on methicillin-resistant Staphylococcus aureus. Foodborne Pathog. Dis. 9, 573-578. doi: 10.1089/fpd.2011.1046

Tabasco, R., Sanchez-Patan, F., Monagas, M., Bartolome, B., Victoria MorenoArribas, M., Pelaez, C., et al. (2011). Effect of grape polyphenols on lactic acid bacteria and bifidobacteria growth: resistance and metabolism. Food Microbiol. 28, 1345-1352. doi: 10.1016/j.fm.2011.06.005

Tehranifar, A., Selahvarzi, Y., Kharrazi, M., and Bakhsh, V. J. (2011). High potential of agro-industrial by-products of pomegranate (Punica granatum L.) as the powerful antifungal and antioxidant substances. Ind. Crops Product 34, 1523-1527. doi: 10.1016/j.indcrop.2011.05.007

Vanella, L., Barbagallo, I., Acquaviva, R., Di Giacomo, C., Cardile, V., Abraham, N. G., et al. (2013a). Ellagic acid: cytodifferentiating and antiproliferative effects in human prostatic cancer cell lines. Curr. Pharm. Des. 19, 2728-2736.

Vanella, L., Di Giacomo, C., Acquaviva, R., Barbagallo, I., Cardile, V., Kim, D. H., et al. (2013b). Apoptotic markers in a prostate cancer cell line: effect of ellagic acid. Oncol. Rep. 30, 2804-2810. doi: 10.3892/or.2013.2757

Vanella, L., Di Giacomo, C., Acquaviva, R., Barbagallo, I., Li Volti, G., Cardile, V., et al. (2013c). Effects of ellagic acid on angiogenic factors in prostate cancer cells. Cancers 5, 726-738. doi: 10.3390/cancers5020726

Vanella, L., Sanford, C. Jr., Kim, D. H., Abraham, N. G., and Ebraheim, N. (2012). Oxidative stress and heme oxygenase-1 regulated human mesenchymal stem cells differentiation. Int. J. Hypertens. 2012:890671. doi: 10.1155/2012/890671

Waldman, M., Bellner, L., Vanella, L., Schragenheim, J., Sodhi, K., Singh, S. P., et al. (2016). Epoxyeicosatrienoic Acids Regulate Adipocyte Differentiation of Mouse 3T3 Cells, Via PGC-1alpha Activation, Which Is Required for HO-1 Expression and Increased Mitochondrial Function. Stem Cells Dev. 25, 1084-1094. doi: $10.1089 /$ scd.2016.0072

Wang, Y. W., and Jones, P. J. (2004). Conjugated linoleic acid and obesity control: efficacy and mechanisms. Int. J. Obes. Relat. Metab. Disord. 28, 941-955. doi: $10.1038 /$ sj.ijo.0802641

Xu, K. Z., Zhu, C., Kim, M. S., Yamahara, J., and Li, Y. (2009). Pomegranate flower ameliorates fatty liver in an animal model of type 2 diabetes and obesity. J. Ethnopharmacol. 123, 280-287. doi: 10.1016/j.jep.2009.03.035

Conflict of Interest Statement: The authors declare that the research was conducted in the absence of any commercial or financial relationships that could be construed as a potential conflict of interest.

Copyright (c) 2019 Sorrenti, Randazzo, Caggia, Ballistreri, Romeo, Fabroni, Timpanaro, Raffaele and Vanella. This is an open-access article distributed under the terms of the Creative Commons Attribution License (CC BY). The use, distribution or reproduction in other forums is permitted, provided the original author(s) and the copyright owner(s) are credited and that the original publication in this journal is cited, in accordance with accepted academic practice. No use, distribution or reproduction is permitted which does not comply with these terms. 